\title{
Overexpression of Nampt in gastric cancer and chemopotentiating effects of the Nampt inhibitor FK866 in combination with fluorouracil
}

\author{
TIE-QIANG BI，XIANG-MING CHE，XIN-HUA LIAO，DAN-JIE ZHANG, \\ HOU-LONG LONG, HAI-JUN LI and WEI ZHAO \\ Department of General Surgery, First Affiliated Hospital of Medical College \\ of Xi'an Jiaotong University, Xi'an 710061, P.R. China
}

Received May 12, 2011; Accepted June 6, 2011

DOI: $10.3892 /$ or.2011.1378

\begin{abstract}
Nicotinamide phosphoribosyltransferase (Nampt), an enzyme involved in the $\mathrm{NAD}^{+}$salvage pathway, is overexpressed and important in the carcinogenesis in several types of cancers. The expression of Nampt and its role in gastric cancer remain largely unknown. In this study, using real-time PCR and Western blotting we found that Nampt was overexpressed at the mRNA and protein levels, respectively, in established gastric cancer cells and human gastric cancer tissues. The specific Nampt inhibitor FK866 repressed gastric cancer cell proliferation, as assessed by MTT assay. Using transwell and soft agar clonogenic assays, we also found that FK866 suppressed gastric cancer cell migration and anchorageindependent growth, respectively. These inhibitory effects of FK866 were accompanied by significantly decreased expression of VEGF, MMP2, MMP9 and NF- $\kappa$ B. As determined by MTT assay and flow cytometry, FK866 also increased the chemosensitivity of gastric cancer cells to fluorouracil by greater inhibition of cell proliferation and the induction of apoptosis. Our findings indicate that Nampt may be a new therapeutic target for gastric cancer.
\end{abstract}

\section{Introduction}

Gastric cancer is the fourth most common malignancy in the world and causes $\sim 800,000$ deaths annually worldwide (1). For patients with recurrent, metastatic, or advanced gastric cancer, fluorouracil (5-FU) is a commonly used chemotherapeutic drug (2). However, the toxic side effects associated with 5-FU remain a significant challenge to its use. The development of

Correspondence to: Dr Xiang-Ming Che, Department of General Surgery, First Affiliated Hospital of Medical College of Xi'an Jiaotong University, Yanta West Road 277, Xi'an 710061, P.R. China E-mail: chexiang@mail.xjtu.edu.cn

Key words: gastric cancer, nicotinamide phosphoribosyltransferase, proliferation, migration, apoptosis, FK866 more effective therapeutic drugs with minimal side effects is crucial, and is dependent on a better understanding of the molecular mechanism underlying gastric carcinogenesis.

Nicotinamide adenine dinucleotide (NAD) is an essential cofactor found in all cells and plays key roles as a carrier of electrons during redox reactions. The rate-limiting enzyme involved in the biosynthesis of NAD from the nicotinamide precursor is nicotinamide phosphoribosyltransferase (Nampt) (3). Increasing evidence demonstrates that Nampt is a multifunctional enzyme and is important in metabolism and immune response as well as cancer (4). Nampt is also known as pre-B-cell colony enhancing factor (PBEF1), a presumptive cytokine (5), and as visfatin, an insulin-mimetic adipocytokine secreted by visceral fat (6) that is also encoded by the PBEFI gene (5).

Cross-talk between the two NAD-dependent enzymes SIRT1 (also known as sirtuin 1 or NAD-dependent deacetylase sirtuins-1) deacetylase and poly(ADP-ribose) polymerase 1 (PARP1) plays a major role in cell viability under stress (7). By binding to and thereby causing the deacetylation of PARP1, SIRT1 protects cells from PARP1-mediated cell death. SIRT1 has also been shown to control PARP1 at the transcriptional level by negatively regulating the PARP1 gene promoter. The activity of SIRT1 can be positively regulated by Nampt, making Nampt a player in promoting cell survival under stress (8).

Nampt was first reported to be overexpressed in colorectal cancer $(9,10)$. It is also overexpressed in prostate cancer and may promote prostate cancer cell survival and growth (8). Consistent with these findings, Nampt was most recently reported to promote prostate cancer cell proliferation and activate ERK-1/2 and p38-induced expression of matrix metalloproteinase (MMP)2 and MMP9. Nampt expression at the mRNA and protein levels is dramatically increased in glioblastoma tissue specimens. In addition, Nampt expression levels in blood are associated with tumor progression in patients with gastric cancer (11) and colorectal cancer (12), suggesting that Nampt may be a biomarker for gastric and colorectal cancers.

FK866, also known as APO866, is a potent and specific small molecule inhibitor of Nampt (13). It suppresses cancer cell growth and induces apoptosis by NAD depletion (13). Of 
note, FK866 selectively inhibits the growth of various kinds of cancer cells, but not normal cells (3). One reasonable explanation for this specificity is that cancer cells are more vulnerable to inhibition of NAD synthesis than normal cells (13-15).

In this study, we demonstrated that Nampt was overexpressed at the mRNA and protein levels in human gastric cancer tissues and in established gastric cancer cells in vitro. FK866 inhibited cell proliferation, migration and anchorageindependent growth of gastric cancer cells and downregulated the expressions of vascular endothelial growth factor (VEGF), MMP2, MMP9 and nuclear factor kappa-light-chainenhancer of activated $\mathrm{B}$ cells $(\mathrm{NF}-\kappa \mathrm{B})$. We also found that FK866 enhanced the antitumor activity of the conventional chemotherapeutic drug 5-FU, which induces cell death by interference with DNA synthesis. Thus, our new findings indicate that FK866 may be a promising therapeutic agent against gastric cancer, either used alone or in combination with 5-FU.

\section{Materials and methods}

Tissue collection. Fresh gastric tumor and adjacent normal tissues were obtained from 3 patients who underwent surgery in May 2010 at the Department of General Surgery, First Affiliated Hospital of Medical College of Xi'an Jiaotong University (Xi'an, China). All patients were clinically and histologically diagnosed with gastric cancer. The protocol and patient informed consent forms were approved by the Ethics Committee of Xi'an Jiaotong University Hospital.

Cell culture and drug treatment. The human gastric cancer cell lines MKN45, SGC7901 and BGC823, and the non-cancer gastric mucosal epithelial cell line GES-1, were obtained from the Institute of Urology, First Affiliated Hospital of Medical College of Xi'an Jiaotong University. All cell lines were maintained in complete Dulbecco's modified Eagle's medium (Invitrogen, Grand Island, NY, USA) supplemented with $10 \%$ fetal bovine serum. Cells were maintained in a humidified $5 \%$ $\mathrm{CO}_{2}$ atmosphere at $37^{\circ} \mathrm{C}$. FK866 was purchased from Cayman Chemical (Ann Arbor, MI, USA). 5-FU (25 mg/ml) was purchased from Tianjin Amino Acids (Tianjin, China). Drugs from stock solutions were diluted into culture medium at the desired working concentrations for in vitro experiments.

Total RNA extraction and real-time reverse transcription polymerase chain reaction ( $q R T-P C R)$. Total RNA was extracted from cultured cells by TRIzol reagent. Subsequently, extracted total RNA was then reverse-transcribed to cDNA with a cDNA synthesis kit (Takara Biochemicals, Kyoto, Japan) according to the manufacturer's instructions. The primers used in the reaction were: Nampt, forward: 5'-AAGAGACTGCTGGCATAGGA-3', reverse: 5'-ACCACAGATACAGGCACTGA-3'; GADPH, forward: 5'-ACCACAGTCCATGCCATCAC-3', reverse: 5'-TCCACCACCCTGTTGCTGTA-3'. Briefly, qRT-PCR for indicated genes was carried out using SYBR Premix Ex Taq (Takara Biochemicals) by an iCycler (Bio-Rad, Hercules, CA) according to the manufacturer's instructions. The program was run with an initial predenaturation step at $95^{\circ} \mathrm{C}$ for $30 \mathrm{sec}$, followed by 40 cycles at $95^{\circ} \mathrm{C}$ for $5 \mathrm{sec}, 55^{\circ} \mathrm{C}$ for $15 \mathrm{sec}$, and $72^{\circ} \mathrm{C}$ for 15 sec. All cDNA samples were synthesized in parallel, and $\mathrm{PCR}$ reactions were run in triplicate. mRNA levels were derived from standard curves and were expressed as relative changes after normalization versus GAPDH mRNA levels.

Western blot assay. Briefly, gastric cancer cells treated with either the vehicle control or $\operatorname{drug}(\mathrm{s})$ were lysed on ice in lysis buffer. Equal amounts of protein were then resolved by $10 \%$ SDS-PAGE and electrotransferred onto a nitrocellulose membrane. The membrane was blocked with $5 \%$ non-fat milk in Tris-buffered saline with $0.1 \%$ Tween-20 at $37^{\circ} \mathrm{C}$ for $1.5 \mathrm{~h}$. The membranes were then incubated with primary antibodies at $4^{\circ} \mathrm{C}$ overnight. Thereafter, membranes were incubated for one hour with horseradish peroxidase-conjugated secondary antibodies corresponding to the primary antibodies. Bands were visualized with a chemiluminescence kit (Pierce, Rockford, IL, USA) according to the manufacturer's instructions. $\beta$-actin served as the loading control. Nampt antibody was purchased from Abcam (Cambridge, MA, USA). Antibodies of VEGF, MMP2, MMP9, NF- $\kappa$ B transcription factor (p65) and $\beta$-actin were purchased from Santa Cruz Biotechnology (Santa Cruz, CA, USA).

Cell viability. Cell viability was measured by the 3-(4,5-dimethylthiazol-2-yl)-2,5-diphenyltetrazolium (MTT) bromide assay. The MTT kit and dimethyl sulfoxide (DMSO) were obtained from Sigma. After incubation with FK866 alone or FK866 plus 5-FU in 96-well plates (Corning, NY, USA) for 24, 48 or $72 \mathrm{~h}, \mathrm{BGC} 823$ cells were then incubated with $2.5 \% \mathrm{MTT}$ solution $(5 \mathrm{mg} / \mathrm{ml})$ at $37^{\circ} \mathrm{C}$ for $4 \mathrm{~h}$. Subsequently, the medium was aspirated from the wells and $150 \mu 1$ DMSO was added to dissolve the tetrazolium crystals. Finally, the optical density (OD) was determined at $490 \mathrm{~nm}$ by a Benchmark Plus microplate reader (Bio-Rad). The tests were repeated in triplicate, and the average OD value was calculated. Cell viability ratio $(\%)$ was calculated as: (average $\mathrm{OD}_{\text {treated group }} /$ average $\mathrm{OD}_{\text {control }}$ ) $\mathrm{x} 100 \%$.

Transwell migration assay. The in vitro cell migration assay was performed by using a modified Boyden chamber inserted with a polyethylene terephthalate filter membrane containing $8-\mu \mathrm{m}$ pores in 24-well plates (Corning). Cells $\left(1 \times 10^{5}\right)$ suspended in $100 \mu \mathrm{l}$ of serum-free medium with various concentrations of FK866 were seeded into the upper compartment of the transwell chamber. The lower chamber was filled with complete medium supplemented with $20 \%$ fetal bovine serum. After incubation for $24 \mathrm{~h}$, the medium in the upper chamber was removed. The cells remaining on the upper surface of the filter membrane were then completely removed by wiping with a cotton swab, and the cells on the opposite surface of the filter membrane were stained with $0.1 \%$ crystal violet for $20 \mathrm{~min}$. The migrated cells were then visualized and counted from 6 randomly selected fields (x200 magnification) under an inverted microscope.

Soft agar clonogenic assay. Firstly, $3 \mathrm{ml}$ of mixture composed of 1.2\% low-melting-point agarose (Promega, Madison, WI, USA) and the same amount of complete medium was poured into each well of a six-well plate (Corning) and allowed to set for $20 \mathrm{~min}$ at room temperature. After BGC823 cells were counted and dispersed into single-cell suspensions, they 
A
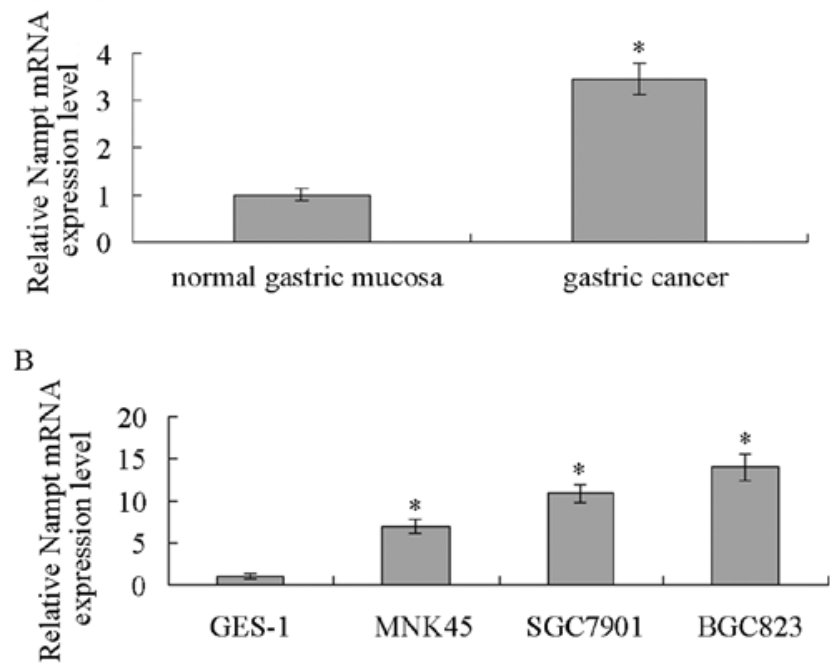

$\mathrm{C}$

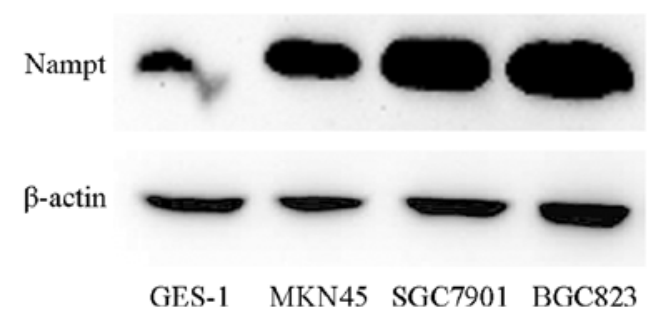

Figure 1. Nampt is overexpressed in gastric cancers. (A) Nampt mRNA expression in gastric cancer tissues and adjacent normal tissues. The bar chart shows quantification of Nampt mRNA expression in gastric cancer tissues and adjacent normal tissues by qRT-PCR. " $\mathrm{P}<0.05$ compared to basal expression of normal tissues. (B) Nampt mRNA expression in 3 gastric cancer cell lines (MKN45, SGC7901, BGC823) and the non-cancer cell line GES-1 by qRT-PCR. Bar chart shows quantification of Nampt mRNA expression in cell lines. ${ }^{*} \mathrm{P}<0.05$, between gastric cancer cell line and GES-1. (C) Nampt protein expression in 3 gastric cancer cell lines and GES-1 using Western blotting. $\beta$-actin was used as a loading control. ${ }^{*} \mathrm{P}<0.05$, between gastric cancer cell line and GES-1.

were resuspended in experimental medium containing $0.6 \%$ agarose to achieve a final agarose concentration of $0.3 \%$. Cell mixture $(2 \mathrm{ml})$ was added to each base layer and allowed to set for $20 \mathrm{~min}$ at room temperature before incubation at $37^{\circ} \mathrm{C}$. Colonies $>100 \mu \mathrm{m}$ were counted after 3 weeks using a calibrated scale. The tests were repeated in triplicate.

Cell apoptosis analysis. After cells were treated with drugs for $48 \mathrm{~h}$ or $72 \mathrm{~h}$, apoptosis was determined using Annexin-V-FITC kit (Joincare Biosciences, Zhuhai, China). Cells were harvested by trypsinization and washed twice with cold phosphate buffered saline (PBS). After centrifugation at $2000 \mathrm{x} \mathrm{g}$ for $5 \mathrm{~min}$, the supernatant was discarded and the pellet was resuspended in $100 \mu \mathrm{l}$ of binding buffer. FITC-labeled Annexin V $(5 \mu \mathrm{l})$ and $10 \mu \mathrm{l}$ of propidium iodide (PI) were added to the cell suspension. After incubation at room temperature for $15 \mathrm{~min}$ in the dark, $400 \mu \mathrm{l}$ of binding buffer was added to each sample. The samples were subsequently analyzed by flow cytometry (BD Biosciences, USA).

Statistical analysis. Data are presented as the mean \pm standard deviation (SD). Significance levels for comparison of differ-
A
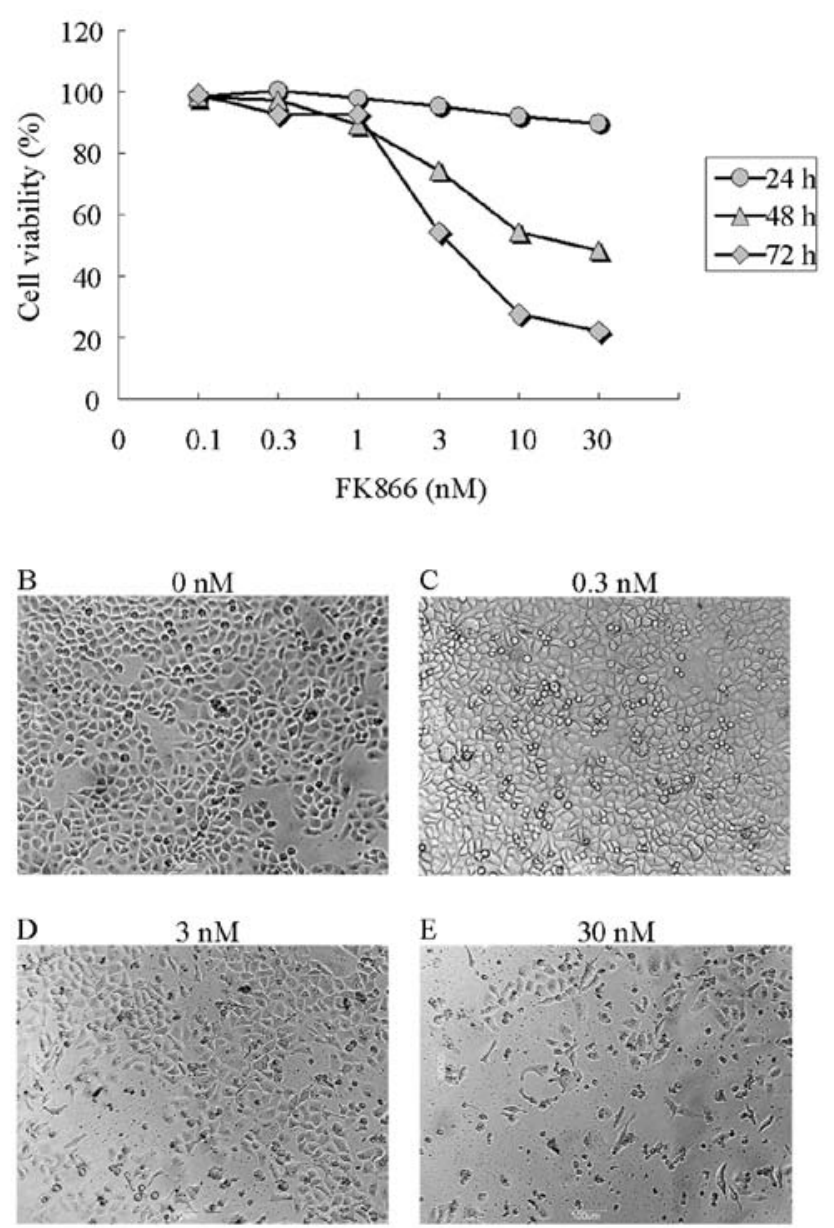

Figure 2. FK866 inhibited gastric cancer proliferation in a time- and dose-dependent manner. (A) The effects of FK866 on cell viability were determined by MTT assay after incubation of BGC 823 gastric cancer cells with indicated concentrations of FAK866 for $24 \mathrm{~h}$ (circles), $48 \mathrm{~h}$ (triangles) or $72 \mathrm{~h}$ (diamonds) respectively. Before being assessed by MTT assay, the cells were visualized with a microscope (x200 magnification) after treating BGC823 cells for $72 \mathrm{~h}$ with FK866 at concentrations of (B) $0 \mathrm{nM}$ (vehicle control), (C) $0.3 \mathrm{nM}$, (D) $3 \mathrm{nM}$, and (E) $30 \mathrm{nM}$.

ences between experimental and control groups were analyzed by Student's t-test. One-way analysis of variance (ANOVA) followed by Student-Newman-Keuls multiple comparison test was employed to calculate the significance of differences between different experimental groups. The differences were considered significant when the probability $(\mathrm{P})$-value was $<0.05$.

\section{Results}

Overexpression of Nampt in gastric cancer tissues and cell lines. Nampt expression at the mRNA level in tumor tissues was significantly increased as compared to adjacent normal tissues (Fig. 1A). Nampt was also consistently overexpressed at the mRNA (Fig. 1B) and protein levels (Fig. 1C) in the three gastric cancer cell lines MKN45, SGC7901 and BGC823, as compared to the non-cancer gastric mucosal epithelial cell line GES-1. The housekeeping gene $\beta$-actin was expressed at a similar level in all 4 cell lines (Fig. 1C). In addition, the gastric cancer cell line BGC823 expressed more Nampt than the other 

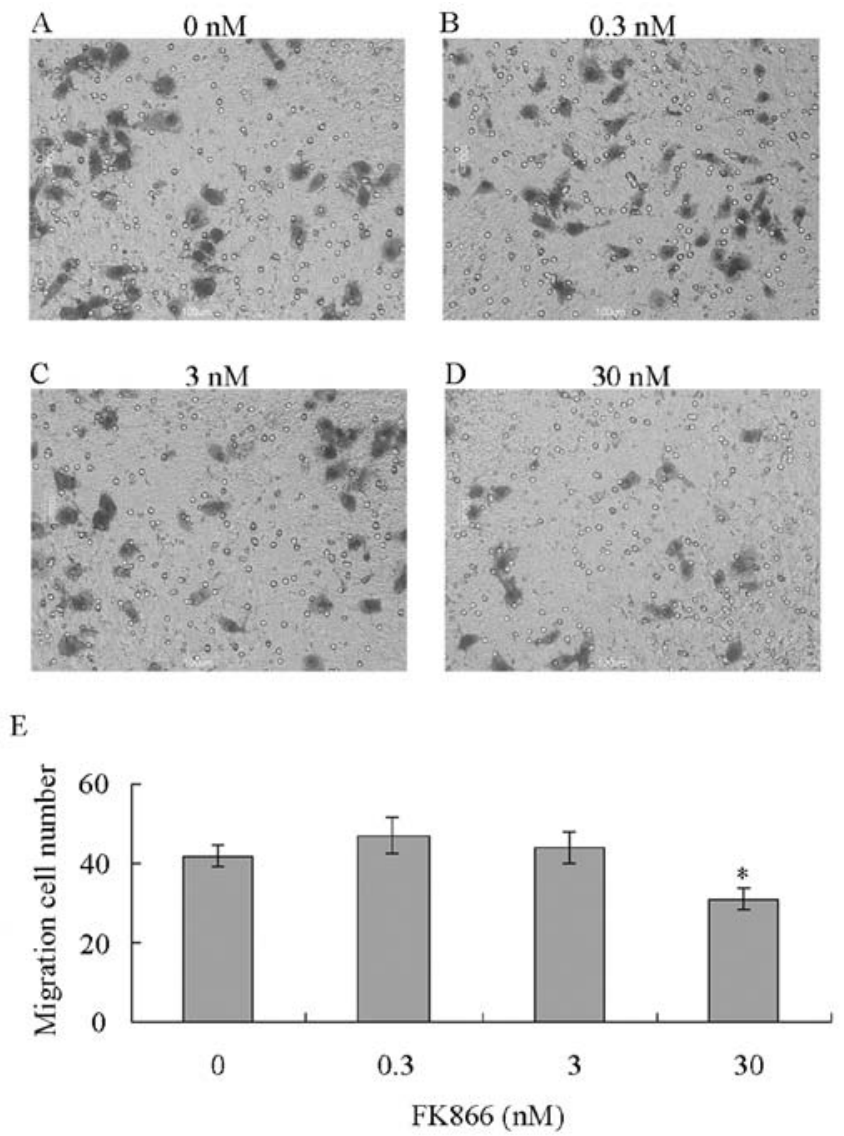

Figure 3. FK866 at $30 \mathrm{nM}$ inhibits BGC823 cell migration. Visualization of cell migration after treating BGC823cells for $24 \mathrm{~h}$ with FK866 at concentrations of (A) $0 \mathrm{nM}$, (B) $0.3 \mathrm{nM}$, (C) $3 \mathrm{nM}$, and (D) $30 \mathrm{nM}$. (E) Quantification of migration activity of cells treated with FK866 at the indicated concentrations for $24 \mathrm{~h} .{ }^{*} \mathrm{P}<0.05$, between the $30 \mathrm{nM}$ group and control group $(0 \mathrm{nM})$.

3 cell lines. We therefore selected the BGC823 cell line for the following studies.

FK866 inhibits gastric cancer proliferation in a time- and dose-dependent manner. FK866 inhibited BGC823 gastric cancer proliferation in a time- and dose-dependent manner (Fig. 2A). No significant effect was observed after BGC823 cells were incubated for $24 \mathrm{~h}$ with FK866, even at the highest test concentration (30 nM). FK866 (3-30 nM) significantly inhibited BGC823 cell proliferation after incubation for either 48 or 72 h (Fig. 2A). Representative images of BGC823 cells treated with either vehicle control or $0.3,3$ or $30 \mathrm{nM} \mathrm{FK} 866$ for $72 \mathrm{~h}$ are shown in Fig. 2B-E.

FK866 inhibits BGC823 cell migration. To test whether FK866 had anti-metastatic properties, we next investigated the effect of FK866 on the migration of BGC823 cells using the transwell assay. The number of cells that migrated to the lower chamber was reduced by FK866 in a concentration-dependent manner (Fig. 3). Incubation of BGC823 cells with $30 \mathrm{nM}$ FK866 for 24 h significantly inhibited BGC823 cell migration (Fig. 3). This inhibitory effect of FK866 on BGC823 cell migration is not likely due to the cytotoxic effect of FK866 because, as shown above, the viability of BGC 823 cells was barely affected by FK866 at $24 \mathrm{~h}$ (Fig. 2A).
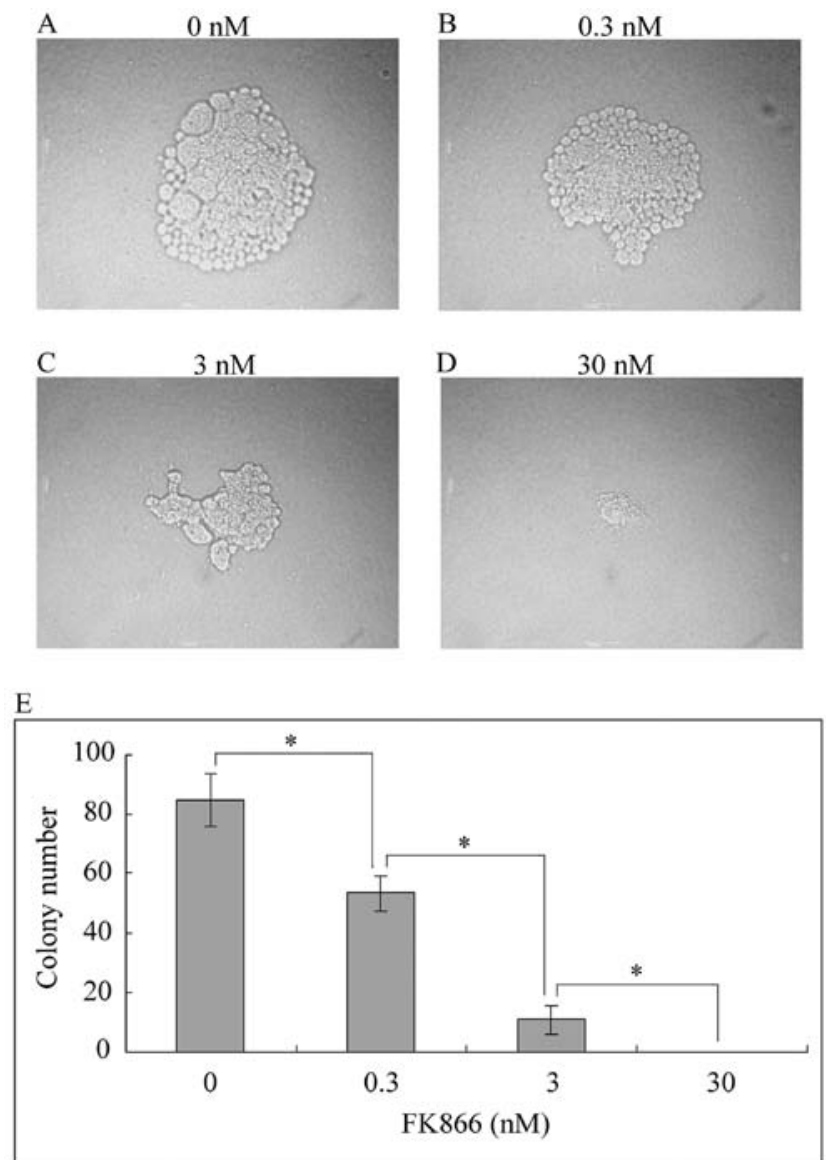

Figure 4. FK866 suppressed anchorage-independent growth of BGC823 cells. Anchorage-independent growth was assessed by colony formation assay. Visualization of colony formation of cells after treating BGC823cells for 3 weeks with FK866 at concentrations of (A) $0 \mathrm{nM}$, (B) $0.3 \mathrm{nM}$, (C) $3 \mathrm{nM}$, and (D) $30 \mathrm{nM}$. (E) Quantification of colony formation assays. " $\mathrm{P}<0.05$, between the indicated two groups.

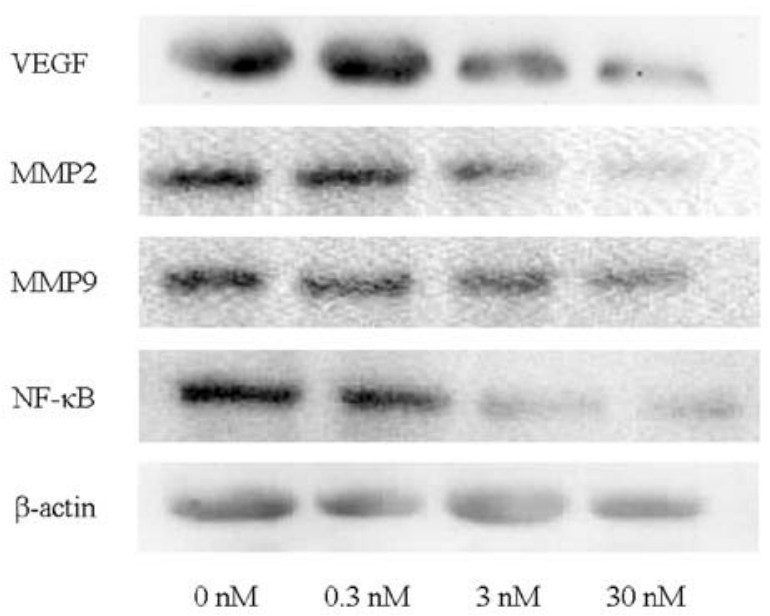

Figure 5. Inhibition of Nampt downregulates the expressions of VEGF, MMP2, MMP9 and NF-кB. BGC823 cells were treated with FK866 $(0,0.3,3$ or $30 \mathrm{nM}$ ) for $48 \mathrm{~h}$. The protein levels of VEGF, MMP2, MMP9, and NF-kB (p65) were analyzed by Western blotting.

FK866 suppresses anchorage-independent growth of BGC823 cells. FK866, in a dose-dependent manner, significantly inhibited BGC823 cell anchorage-independent growth, as assessed 
A

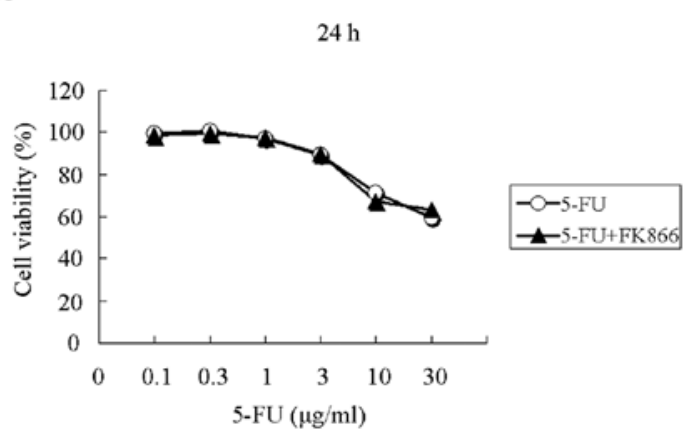

B

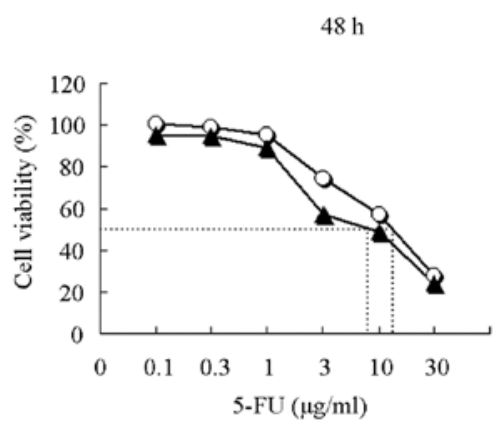

$\mathrm{C}$

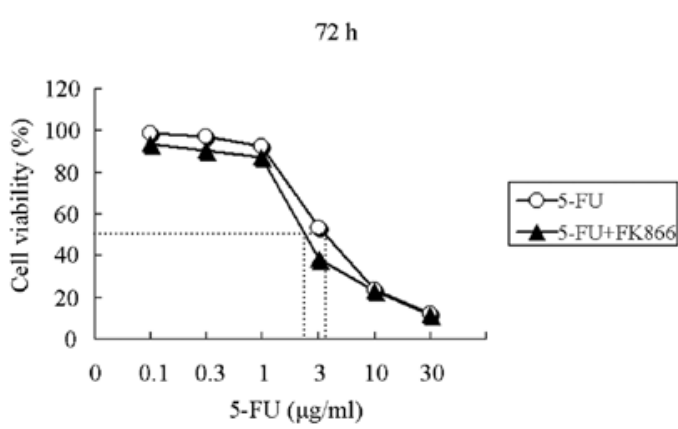

Figure 6. FK866 increases the chemosensitivity of BGC823 cells to 5-FU. BGC823 cells were seeded in 96-well plates, treated with 5-FU alone (open circles), or with 5-FU plus one nM FK866 (filled triangles) for $24 \mathrm{~h}$ (A), $48 \mathrm{~h}$ (B) or $72 \mathrm{~h}(\mathrm{C})$ respectively. Cell viability was determined by MTT assay.

by colony formation (Fig. 4). The lowest tested concentration of FK866 (i.e., $0.3 \mathrm{nM}$ ) was sufficient to suppress anchorageindependent growth of BGC823 cells (compare Fig. 4A to B and $\mathrm{E})$.

Inhibition of Nampt downregulates the expression of VEGF, $M M P 2, M M P 9$ and $N F-\kappa B$. In order to delineate the molecular mechanism underlying regulation of Nampt in gastric cancer, we next sought to investigate the effect of FK866 on expression of some downstream proteins of Nampt. Incubation of BGC823 cells with FK866 for $48 \mathrm{~h}$ inhibited the expression of VEGF, MMP2, MMP9 and NF- $\mathrm{B}$ (p65 subunit) in a dosedependent manner (Fig. 5).

FK866 increases chemosensitivity of BGC823 cells to 5-FU. No significant difference in BGC823 cell viability was observed between 5-FU alone and 5-FU plus FK866 (1 nM) treatments for $24 \mathrm{~h}$ (Fig. 6A). However, the treatment of 5-FU plus FK866, as compared to 5-FU alone, significantly inhib-
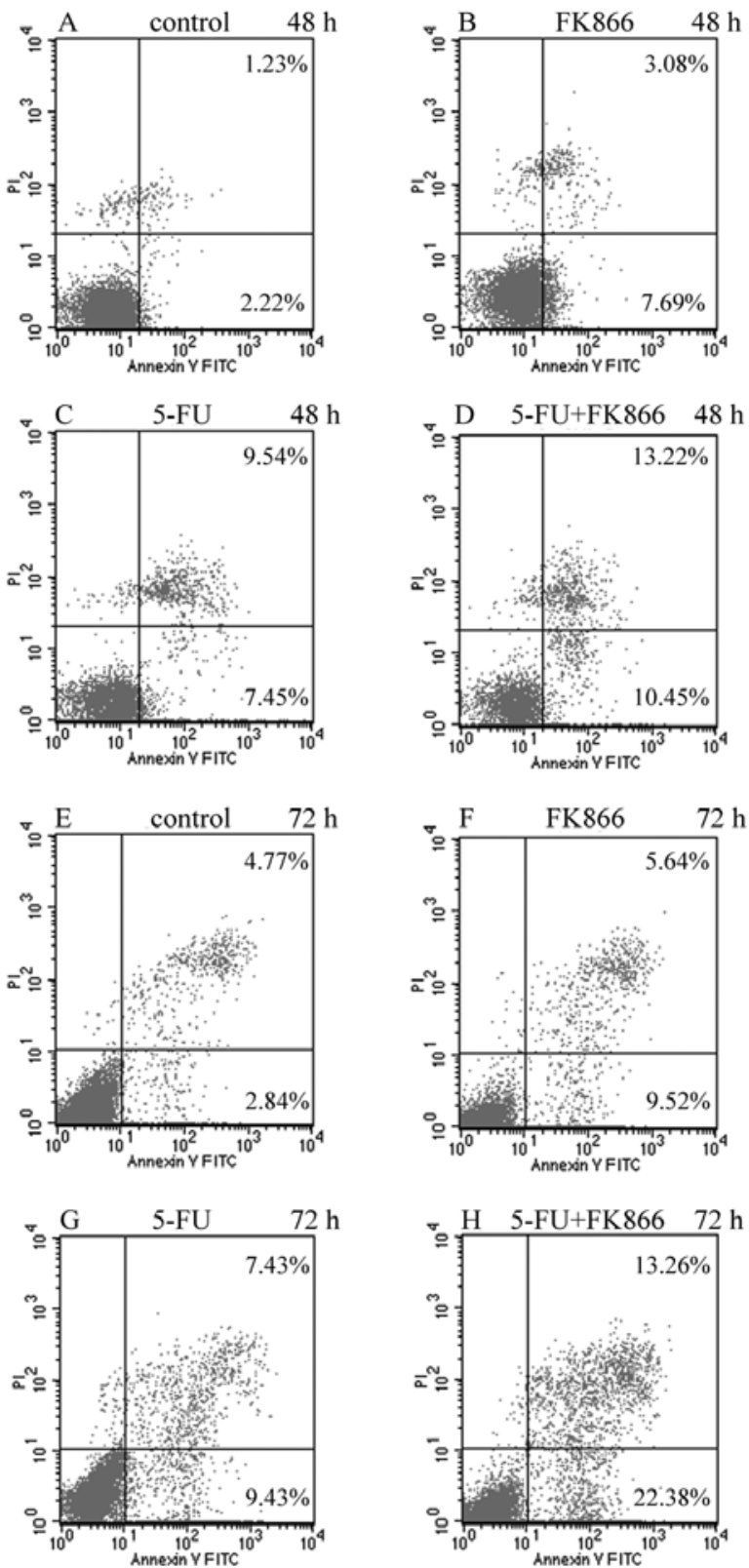

Figure 7. FK866 increases the chemosensitivity of BGC823 cells to 5-FU-induced apoptosis. Apoptotic BGC823 cells after (A) no-treatment, or (B) treatment with one nM FK866 only, or (C) $3 \mu \mathrm{g} / \mathrm{ml} 5-\mathrm{FU}$ only, or (D) 5-FU plus FK866 for 48 or $72 \mathrm{~h}$ (E-H for the indicated treatments). Apoptosis was assessed by flow cytometry. Significant apoptosis was induced by $5-\mathrm{FU}$ plus FK866 as compared to other groups.

ited BGC823 cell growth at both 48 and $72 \mathrm{~h}$ (Fig. 6B and $\mathrm{C}$, respectively). The half maximal inhibitory concentration $\left(\mathrm{IC}_{50}\right)$ of 5-FU was lowered in the presence of FK866 (Fig. 6B and $\mathrm{C}$ ).

Consistent with the above results, cell apoptosis was increased in BGC823 cells that had been incubated in 5-FU combined with FK866 (1 nM) for $48 \mathrm{~h}$ or $72 \mathrm{~h}$, compared to those that had been treated with 5-FU alone (Fig. 7).

\section{Discussion}

In this study, we found the overexpression of Nampt in established gastric cancer cells as well as in human gastric cancer 
tissues. The Nampt inhibitor FK866 repressed cell proliferation, migration and anchorage-independent growth of gastric cancer cells. Furthermore, FK866 also increased chemosensitivity of gastric cancer cells to 5-FU, as evidenced by increased apoptosis and inhibition of cell proliferation in the combined FK866 and 5-FU treatments. Nampt has been reported to be overexpressed in several cancers $(8,9,16)$. To our knowledge, this is the first demonstration of the overexpression of Nampt in established gastric cancer cell lines as well as surgically resected gastric tumors. Previous studies indicate that Nampt upregulates cell proliferation in normal human epithelial cells and vascular smooth muscle cells $(17,18)$. Our results suggest that Nampt might also be important in the abnormal proliferation of gastric cancer cells.

$\mathrm{NF}-\kappa \mathrm{B}$ plays important roles in many cellular processes. Recent studies indicate that $\mathrm{NF}-\kappa \mathrm{B}$ activation can be induced by Nampt in human endothelial cells and macrophages $(19,20)$. Consistent with these reports, another recent report also demonstrated that Nampt upregulates MMP2 and MMP9 by activating the $\mathrm{NF}-\kappa \mathrm{B}$ pathway in human vascular endothelial cells (17). Therefore, Nampt-induced cell proliferation and migration may be, at least partly, through the activation of the NF- $\kappa \mathrm{B}$ pathway. Furthermore, the abnormal expression of $N F-\kappa B$ frequently occurs in gastric cancer (21) and NF- $\mathrm{NB}$ regulates many genes involved in cell proliferation and migration, including VEGF and MMP2 and MMP9 (17,22). Our present study demonstrated that the highly specific Nampt inhibitor FK866 reduced the expression of VEGF, MMP2, MMP9 and NF- $\mathrm{NB}$ in gastric cancer cells. Therefore, our results support the conclusion that Nampt may be important in cell proliferation by positively regulating VEGF, MMP2, MMP9 and NF- $\mathrm{KB}$ in BGC823 gastric cancer cells.

It is now well established that migration and anchorageindependent growth are important in cancer metastasis (23). Our present results showed that the Nampt inhibitor FK866 inhibited gastric cancer cell migration and anchorageindependent growth in a dose-dependent manner. In addition, FK866 induced gastric cancer cell apoptosis in a dose- and time-dependent manner. Taken together, our findings suggest that Nampt has an important role in regulating initiation and metastasis of gastric cancer. Nampt overexpression is known to contribute to tumor cell survival and proliferation in prostate cancer $(8,24)$. This indicates that the blockade of the Namptstimulated signal pathway by this specific Nampt inhibitor may have therapeutic implications for the treatment of gastric cancer in which Nampt is overexpressed.

Nampt is associated with drug resistance in established cancer cell lines and human tumor tissues $(25,26)$. Inhibition of Nampt increases sensitivity of THP-1 and K562 leukemia cells to 1-methyl-3-nitro-1-nitrosoguanidinium (MNNG), which is a commonly used drug in chemotherapy against leukemia (27). This finding indicates that inhibition of Nampt may contribute to the sensitivity of cells to chemotherapy in malignant disease.

One of the most important NAD-dependent enzymes is PARP1, whose activation is one of the early DNA damage responses (28). It is possible that the NAD-depleting compound FK866 may be administered in combination with genotoxic drugs, in particular DNA damaging drugs, to compromise DNA repair capacity. The antimetabolite 5-FU may interfere with DNA synthesis by blocking thymidylate synthetase and lead to inhibition of DNA chain elongation, DNA stability alternation, and single strand breakage. Therefore, 5-FU and FK866 targets totally different pathways.

In this study, a low dose of FK866 (1 nM) increased the sensitivity of gastric cancer cells to 5-FU, effecting further inhibition of cell proliferation and the induction of apoptosis. These chemopotentiating effects of FK866 may be because FK866 reduces NAD synthesis and thereby contributes to the significant cytotoxicity of 5-FU. Therefore, our new findings indicate that Nampt may also be associated with drug resistance in gastric cancer cells and might be a potential therapeutic target to eradicate chemoresistant gastric cancer.

In conclusion, we found that Nampt was overexpressed in established gastric cancer cells and human gastric cancer tissues. The Nampt inhibitor FK866 suppressed gastric cancer cell proliferation, migration and anchorage-independent growth, probably by downregulating the expressions of VEGF, MMP2, MMP9 and NF- $\kappa$ B. FK866 also increased the chemosensitivity of gastric cancer cells to 5-FU. Our findings may pave a way for the development of a novel strategy to enhance the chemosensitivity of gastric cancer.

\section{Acknowledgements}

We thank Dr Guorong Wang (Shannxi Provincial People's Hospital) and the staff at the Genetic Disease Research Institution of Xi'an Jiaotong University for their technical assistance.

\section{References}

1. Jemal A, Bray F, Center MM, Ferlay J, Ward E and Forman D: Global cancer statistics. CA Cancer J Clin 61: 69-90, 2011.

2. Glimelius B, Ekström K, Hoffman K, et al: Randomized comparison between chemotherapy plus best supportive care with best supportive care in advanced gastric cancer. Ann Oncol 8: 163-168, 1997.

3. Bi TQ and Che XM: Nampt/PBEF/visfatin and cancer. Cancer Biol Ther 10: 119-125, 2010.

4. Gallí M, Van Gool F, Rongvaux A, Andris F and Leo O: The nicotinamide phosphoribosyltransferase: a molecular link between metabolism, inflammation, and cancer. Cancer Res 70: 8-11, 2010.

5. Samal B, Sun Y, Stearns G, Xie C, Suggs S and McNiece I: Cloning and characterization of the cDNA encoding a novel human pre-B-cell colony-enhancing factor. Mol Cell Biol 14: 1431-1437, 1994.

6. Fukuhara A, Matsuda M, Nishizawa M, et al: Visfatin: a protein secreted by visceral fat that mimics the effects of insulin. Science 307: 426-430, 2005.

7. Rajamohan SB, Pillai VB, Gupta M, et al: SIRT1 promotes cell survival under stress by deacetylation-dependent deactivation of poly(ADP-ribose) polymerase 1. Mol Cell Biol 29: 4116-4129, 2009.

8. Wang B, Hasan MK, Alvarado E, Yuan H, Wu H and Chen WY: NAMPT overexpression in prostate cancer and its contribution to tumor cell survival and stress response. Oncogene 30: 907-921, 2011.

9. Hufton SE, Moerkerk PT, Brandwijk R, de Bruïne AP, Arends JW and Hoogenboom HR: A profile of differentially expressed genes in primary colorectal cancer using suppression subtractive hybridization. FEBS Lett 463: 77-82, 1999.

10. Van Beijnum JR, Moerkerk PT, Gerbers AJ, de Bruïne AP, Arends JW, Hoogenboom HR and Hufton SE: Target validation for genomics using peptide-specific phage antibodies: a study of five gene products overexpressed in colorectal cancer. Int J Cancer 101: 118-127, 2002. 
11. Nakajima TE, Yamada Y, Hamano T, et al: Adipocytokine levels in gastric cancer patients: resistin and visfatin as biomarkers of gastric cancer. J Gastroenterol 44: 685-690, 2009.

12. Nakajima TE, Yamada Y, Hamano T, et al: Adipocytokines as new promising markers of colorectal tumors: adiponectin for colorectal adenoma, and resistin and visfatin for colorectal cancer. Cancer Sci 101: 1286-1291, 2010.

13. Hasmann M and Schemainda I: FK866, a highly specific noncompetitive inhibitor of nicotinamide phosphoribosyltransferase, represents a novel mechanism for induction of tumor cell apoptosis. Cancer Res 63: 7436-7442, 2003.

14. Nahimana A, Attinger A, Aubry D, et al: The NAD biosynthesis inhibitor APO866 has potent antitumor activity against hematologic malignancies. Blood 113: 3276-3286, 2009.

15. Holen K, Saltz LB, Hollywood E, Burk K and Hanauske AR: The pharmacokinetics, toxicities, and biologic effects of FK866, a nicotinamide adenine dinucleotide biosynthesis inhibitor. Inves New Drugs 26: 45-51, 2008.

16. Reddy PS, Umesh S, Thota B, et al: PBEF1/NAmPRTase/ Visfatin: a potential malignant astrocytoma/glioblastoma serum marker with prognostic value. Cancer Biol Ther 7: 663-668, 2008

17. Adya R, Tan BK, Chen J and Randeva HS: Nuclear factor-kappaB induction by visfatin in human vascular endothelial cells: its role in MMP-2/9 production and activation. Diabetes Care 31: 758-760, 2008

18. Wang P, Xu TY, Guan YF, Su DF, Fan GR and Miao CY: Perivascular adipose tissue-derived visfatin is a vascular smooth muscle cell growth factor: role of nicotinamide mononucleotide. Cardiovasc Res 81: 370-380, 2009.

19. Lee WJ, Wu CS, Lin H, et al: Visfatin-induced expression of inflammatory mediators in human endothelial cells through the NF-kappaB pathway. Int J Obes (Lond) 33: 465-472, 2009.
20. Fan Y, Meng S, Wang Y, Cao J and Wang C: Visfatin/PBEF/ Nampt induces EMMPRIN and MMP-9 production in macrophages via the NAMPT-MAPK (p38, ERK1/2)-NF- $\kappa$ B signaling pathway. Int J Mol Med 27: 607-615, 2011.

21. Mino K, Ozaki M, Nakanishi K, et al: Inhibition of nuclear factorkappaB suppresses peritoneal dissemination of gastric cancer by blocking cancer cell adhesion. Cancer Sci 102: 1052-1058, 2011.

22. Karin M and Greten FR: NF-kappaB: linking inflammation and immunity to cancer development and progression. Nat Rev Immunol 5: 749-759, 2005.

23. Bacac M and Stamenkovic I: Metastatic cancer cell. Annu Rev Pathol 3: 221-247, 2008.

24. Patel ST, Mistry T, Brown JE, Digby JE, Adya R, Desai KM and Randeva HS: A novel role for the adipokine visfatin/pre-B cell colony-enhancing factor 1 in prostate carcinogenesis. Peptides 31: 51-57, 2010.

25. Folgueira MA, Carraro DM, Brentani H, et al: Gene expression profile associated with response to doxorubicin-based therapy in breast cancer. Clin Cancer Res 11: 7434-7443, 2005

26. Yang H, Yang T, Baur JA, et al: Nutrient-sensitive mitochondrial $\mathrm{NAD}^{+}$levels dictate cell survival. Cell 130: 1095-1107, 2007.

27. Pogrebniak A, Schemainda I, Azzam K, Pelka-Fleischer R, Nüssler $\mathrm{V}$ and Hasmann M: Chemopotentiating effects of a novel NAD biosynthesis inhibitor, FK866, in combination with antineoplastic agents. Eur J Med Res 11: 313-321, 2006.

28. Herceg Z and Wang ZQ: Functions of poly(ADP-ribose) polymerase (PARP) in DNA repair, genomic integrity and cell death. Mutat Res 477: 97-110, 2001. 